Supporting Information

\title{
Cost-effective, flexible, and colorful dynamic displays: removing underlying conducting layers from polymer-based electrochromic devices
}

Elin L. Howard ${ }^{1,2}$; Anna M. Österholm ${ }^{1, *}$; D. Eric Shen ${ }^{1}$; L. Prerana Panchumarti ${ }^{\text {}}$; Carlos Pinheiro ${ }^{2}$; John R. Reynolds ${ }^{1}$

${ }^{1}$ School of Chemistry and Biochemistry, School of Materials Science and Engineering, Center for Organic Photonics and Electronics, Georgia Tech Polymer Network, Georgia Institute of Technology, Atlanta, Georgia 30332, United States

${ }^{2}$ Ynvisible Interactive Inc., Engesserstrasse 4a, 79108 Freiburg im Breisgau, Germany

* Corresponding author: anna.osterholm@chemistry.gatech.edu

\section{EXPERIMENTAL SECTION}

\section{Materials and Methods}

ECP-Orange ( $\left.\mathrm{M}_{\mathrm{n}}: 21 \mathrm{~kg} / \mathrm{mol}\right)$, ECP-Magenta $\left(\mathrm{M}_{\mathrm{n}}: 18 \mathrm{~kg} / \mathrm{mol}\right)$, ECP-Purple $\left(\mathrm{M}_{\mathrm{n}}: 15 \mathrm{~kg} / \mathrm{mol}\right)$, ECPGreen $\left(\mathrm{M}_{\mathrm{n}}: 47 \mathrm{~kg} / \mathrm{mol}\right)$, and ECP-Blue $\left(\mathrm{M}_{\mathrm{n}}: 5 \mathrm{~kg} / \mathrm{mol}\right)$ were all synthesized via direct (hetero)arylation polymerization, as previously reported. ${ }^{1-5}$ For the thin film characterization, the ECPs were sprayed onto ITO/glass slides (Delta Technologies Ltd., $25 \times 75 \times 0.7 \mathrm{~mm}^{3}$, sheet resistance $8-12 \Omega / \mathrm{sq}$, cleaned by sonication in toluene, acetone, and isopropanol) from a $4 \mathrm{mg} / \mathrm{mL}$ polymer solution in toluene (ECP-Orange, ECP-Purple, and ECP-Green) or $\mathrm{CHCl}_{3}$ (ECP-Blue and ECP-Magenta) using an Iwata Eclipse HP-BC airbrush with an optimized argon pressure of approximately $20 \mathrm{psi}$. The films were coated to a comparable optical density $\left(1.0 \pm 0.1\right.$ at $\lambda_{\max }$ in the colored state), which resulted in an average thickness of $297 \mathrm{~nm} \pm 4 \mathrm{~nm}$ for ECP-Orange, 269 $\mathrm{nm} \pm 8 \mathrm{~nm}$ for ECP-Magenta, $243 \mathrm{~nm} \pm 22 \mathrm{~nm}$ for ECP-Purple, $183 \mathrm{~nm} \pm 8 \mathrm{~nm}$ for ECP-Blue, and $293 \mathrm{~nm} \pm 17 \mathrm{~nm}$ for ECP-Green. The thin film experiments were performed in a three-electrode electrochemical cell consisting of a $\mathrm{Ag} / \mathrm{Ag}^{+}$pseudoreference electrode $\left(\mathrm{E}_{1 / 2}\right.$ for $\left.\mathrm{Fc} / \mathrm{Fc}^{+}: 0.08 \mathrm{~V}\right)$, and a Pt flag counter electrode. The electrolyte consisted of 0.5 tetrabutylammonium 
hexafluorophosphate $\left(\mathrm{TBAPF}_{6}\right)$ dissolved in propylene carbonate. The $\mathrm{TBAPF}_{6}$ was recrystallized from hot ethanol and the propylene carbonate was passed through a solvent purification system before use. All samples were electrochemically conditioned using cyclic voltammetry for 10 cycles at $50 \mathrm{mV} / \mathrm{s}$ (from $-0.5 \mathrm{~V}$ to $0.8 \mathrm{~V}$ for ECP-Orange, -Green, and -Purple and from $-0.8 \mathrm{~V}$ to $0.8 \mathrm{~V}$ for ECP-Magenta and ECP-Blue). The in situ spectroscopic analyses were then performed by an Ocean Optics USB2000+ fiber-optic spectrophotometer and an Agilent Cary 5000 spectrophotometer in $1 \mathrm{~cm}$ path length quartz cuvettes. The potential was controlled with an EG\&G PAR 273A potentiostat/galvanostat under CorrWare control. For the spectroelectrochemical measurements, all films were held at the measured potential for 20 seconds prior to recording the spectrum. The switching kinetics were probed by measuring the absorbance at $\lambda_{\max }$ as the film was switched between the colored and colorless state using pulse lengths ranging from 10 to 0.25 seconds. The optical memory was evaluated by applying a reducing or oxidizing potential for 30 seconds before going to open circuit.

For the moving front experiments, the working electrode was a glass slide $(25 \times 75 \times 0.7$ $\mathrm{mm}^{3}$ ) partially coated with evaporated gold. These electrodes were made by first cleaning the glass slides by sonicating them in sodium dodecyl sulfate/water, water, acetone, and isopropanol for 5 minutes each. Kapton tape was then used to cover the bottom $2 \mathrm{~cm}$ of the glass slides, defining the edge of the electrode. The taped slides were brought into a thermal evaporator where $150 \mathrm{~nm}$ thick gold layer was deposited onto $5 \mathrm{~nm}$ thick chromium adhesion layer at roughly 1-2 x 10${ }^{5} \mathrm{mBar}$. The ECP films were then deposited via spray coating, as described above, so that $\sim 1 \mathrm{~cm}$ of the ECP was on the evaporated Au portion of the slide, and $\sim 2 \mathrm{~cm}$ of the ECP was on the glass portion of the slide (see photo and schematic in Fig. S3). The potential was controlled with an EG\&G PAR 273A potentiostat/galvanostat under CorrWare control in a photobooth under D50 illumination. Before starting the experiment, an initial photo of the cell was taken at open circuit. Then an oxidizing potential $\left(0.4 \mathrm{~V}\right.$ for ECP-Blue and $0.7 \mathrm{~V} \mathrm{vs.} \mathrm{Fc} / \mathrm{Fc}^{+}$for the other ECPs) was applied to the working electrode and a video was recorded for the first 30 seconds, followed by photos taken in one-minute intervals up to 5 minutes, and then five-minute intervals up to 15 minutes. Following this, a reducing potential (-1.2 V for ECP-Blue, $-0.9 \mathrm{~V}$ for ECP-Magenta, and $-0.5 \mathrm{~V}$ vs. $\mathrm{Fc} / \mathrm{Fc}^{+}$for the rest) was applied to the working electrode.

For the solid-state conductivity experiments, the ECPs were blade coated using a Zehtner blade coater onto $2.5 \times 2.5 \mathrm{~cm}$ glass slides (blade gap $100 \mu \mathrm{m}$ ) to an optical density ranging from 
0.6 to 1 . The blade coating parameters are summarized in Table S1. A Bruker DektakXT profilometer was then used to measure the film thickness.

Table S1. Concentration, solvent, and blade coating parameters for the various ECPs.

\begin{tabular}{|c|c|c|c|}
\hline Polymer & Ink Concentration & Blade Speed & Avg. Ink Volume \\
\hline ECP-Orange & $40 \mathrm{mg} \mathrm{ml}^{-1}$ in toluene & $10 \mathrm{~mm} \mathrm{~s}^{-1}$ & $6 \mu \mathrm{L}$ \\
\hline ECP-Magenta & $40 \mathrm{mg} \mathrm{ml}^{-1}$ in CHCl & $15 \mathrm{~mm} \mathrm{~s}_{3}^{-1}$ & $15 \mu \mathrm{L}$ \\
\hline ECP-Purple & $40 \mathrm{mg} \mathrm{ml}^{-1}$ in toluene & $22 \mathrm{~mm} \mathrm{~s}^{-1}$ & $20 \mu \mathrm{L}$ \\
\hline ECP-Blue & $40 \mathrm{mg} \mathrm{ml}^{-1}$ in $\mathrm{CHCl}_{3}$ & $5 \mathrm{~mm} \mathrm{~s}^{-1}$ & $5 \mu \mathrm{L}$ \\
\hline ECP-Green & $20 \mathrm{mg} \mathrm{ml}^{-1}$ in toluene & $5 \mathrm{~mm} \mathrm{~s}^{-1}$ & $12.5 \mu \mathrm{L}$ \\
\hline
\end{tabular}

The electrochemical conductance measurements were performed using an electrochemical cell and interdigitated $\mathrm{Au}$ microelectrodes (IDA1-Au) from MicruX Technologies in $0.5 \mathrm{M} \mathrm{TBAPF}_{6} / \mathrm{PC}$. The potential was controlled using a WaveDriver 200 bipotentiostat from PINE research. $\mathrm{A} \mathrm{Ag} / \mathrm{Ag}^{+}$was used as the pseudoreference electrode (calibrated versus $\mathrm{Fc} / \mathrm{Fc}^{+}=$ $70 \mathrm{mV}$ ). The ECP films were deposited onto masked interdigitated electrodes (IDE) via spray coating to thicknesses that were comparable to those used for the spectroelectrochemical experiments $(260 \mathrm{~nm} \pm 30 \mathrm{~nm})$. A glass substrate of the same thickness as the IDE was sprayed simultaneously and used to determine the film thickness with using a Bruker DektakXT profilometer. For the experiments, one set of working electrodes were held at a constant DC potential (in $0.05-0.1 \mathrm{~V}$ increments from $-0.8 \mathrm{~V}$ or $-0.5 \mathrm{~V}$ to $0.8 \mathrm{~V}$ vs. $\mathrm{Ag} / \mathrm{Ag}^{+}$and back) while the other working electrodes were scanned $\pm 5 \mathrm{mV}$ relative to the constant DC potential at a scan rate of $0.5 \mathrm{mV} / \mathrm{s}$. The conductance was extracted from slope of the generated $i-V$ curve and then normalized to film thickness to obtain the conductivity using the equation $\sigma=$ conductance $\mathrm{x}$ $(\mathrm{D} / \mathrm{nLT})$ where $\mathrm{D}, \mathrm{n}, \mathrm{L}$, and $\mathrm{T}$ denotes the electrode spacing, the number of electrodes, the length of the electrode, and the film thickness. We do note though that dimensional normalization of conductance data to provide conductivity values is not straightforward due to complications associated thickness scaling of the active layer. The transport characteristics for films on small, interdigitated electrodes do not necessarily scale linearly, especially as the film thickness exceeds the thickness of the underlying contacts, as outlined by Salinas et al. ${ }^{6}$ For this reason, we ensured that all samples were coated to a comparable thickness. 


\section{Device Fabrication}

The flexible EC devices were fabricated using a lateral device architecture (Fig. 1). The substrate was a $125 \mu \mathrm{m}$ thick PET Melinex 504 (Dupont), the electrical contacts were screen printed using silver paste purchased from ECM, the counter electrode was screen printed PEDOT:PSS paste from Heraeus, and the electrolyte is a $\mathrm{Li}^{+}$-based UV curable gel electrolyte from Ynvisible Interactive Inc. The silver paste and the PEDOT:PSS paste were screen printed using a flat-bed LAB 1000 screen-printer from Thieme. Both materials were cured thermally in a Jetdryer Transfer 4M JD TR 40009 from Acosgraf $\left(1-3\right.$ minutes at $\left.100{ }^{\circ} \mathrm{C}-130{ }^{\circ} \mathrm{C}\right)$. The UV curable electrolyte was knife-coated using a K Control Coater from RK PrintCoat. The electrolyte was cured using a mercury lamp H-type from Acosgraf $\left(250 \mathrm{~W}, 250 \mathrm{~mW} / \mathrm{cm}^{2}\right.$, distance to lamp 5 $\mathrm{cm}$, irradiation time ca. 1 minute). A small segment of screen printed PEDOT:PSS connected the screen printed silver outside the electrolyte area to the ECP pixel inside the electrolyte area. Photos and videos were taken in a photobooth with D50 illumination while the voltage was controlled with an EG\&G PAR 273A potentiostat/galvanostat under CorrWare control. Videos were taken for the first 30 seconds of oxidation, and the first 30 seconds of reduction. The voltage window used for ECP-Magenta and ECP-Green pixels was $-0.5 \mathrm{~V}$ and $0.5 \mathrm{~V}$, whereas the voltage window used for the ECP-Blue pixels was $-1 \mathrm{~V}$ and $1 \mathrm{~V}$. The switching kinetics were measured in an Agilent Cary 5000 spectrophotometer using a $0.5 \mathrm{~cm}$ aperture mask. For ECP-Blue cycles consisted of $30 \mathrm{~s}$ bleaching and $30 \mathrm{~s}$ coloration, for ECP-Magenta cycles consisted of 10 minutes

bleaching and 10 minutes coloration, and for ECP-Green cycles consisted of 60 minutes bleaching and 60 minutes coloration. 

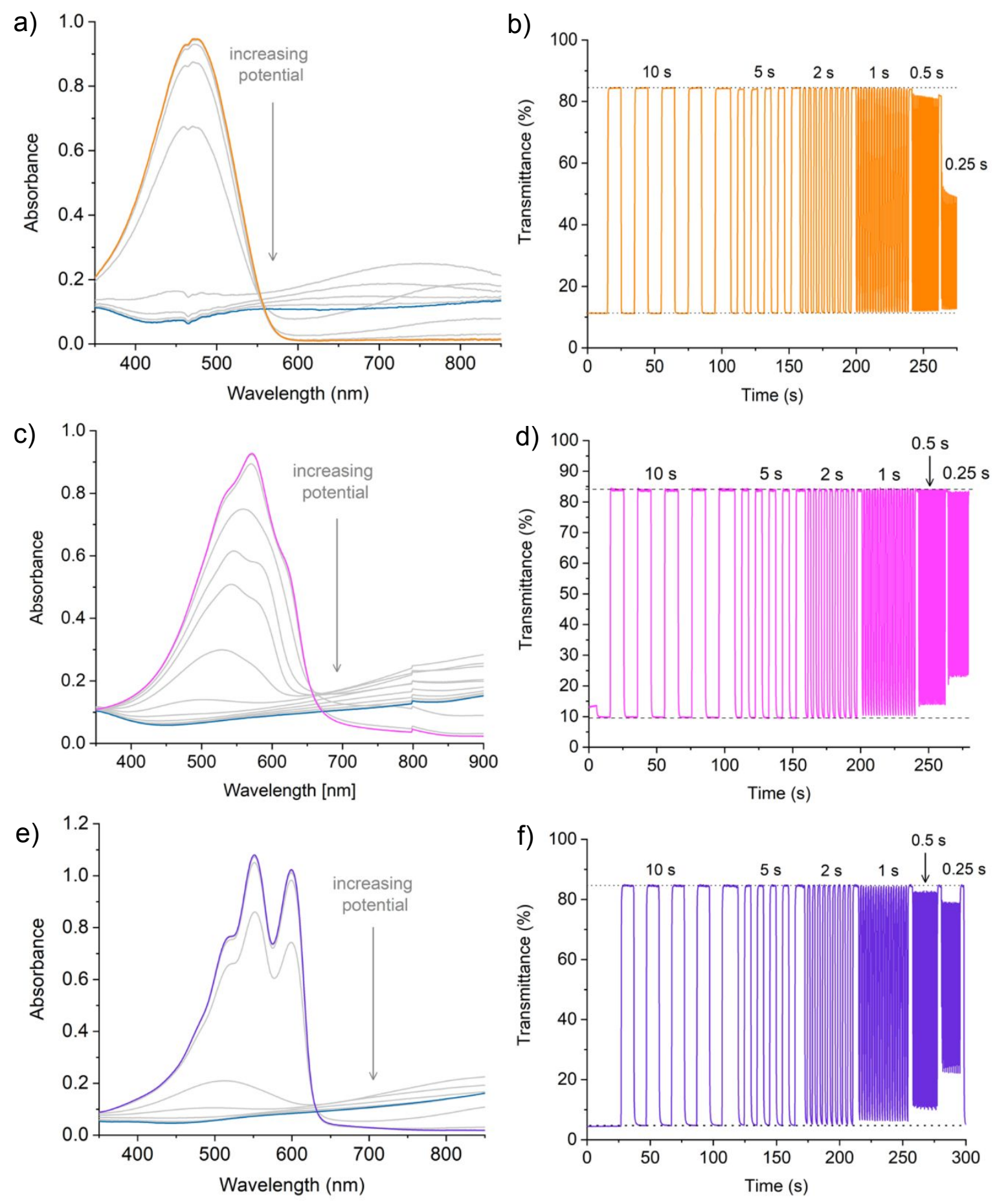

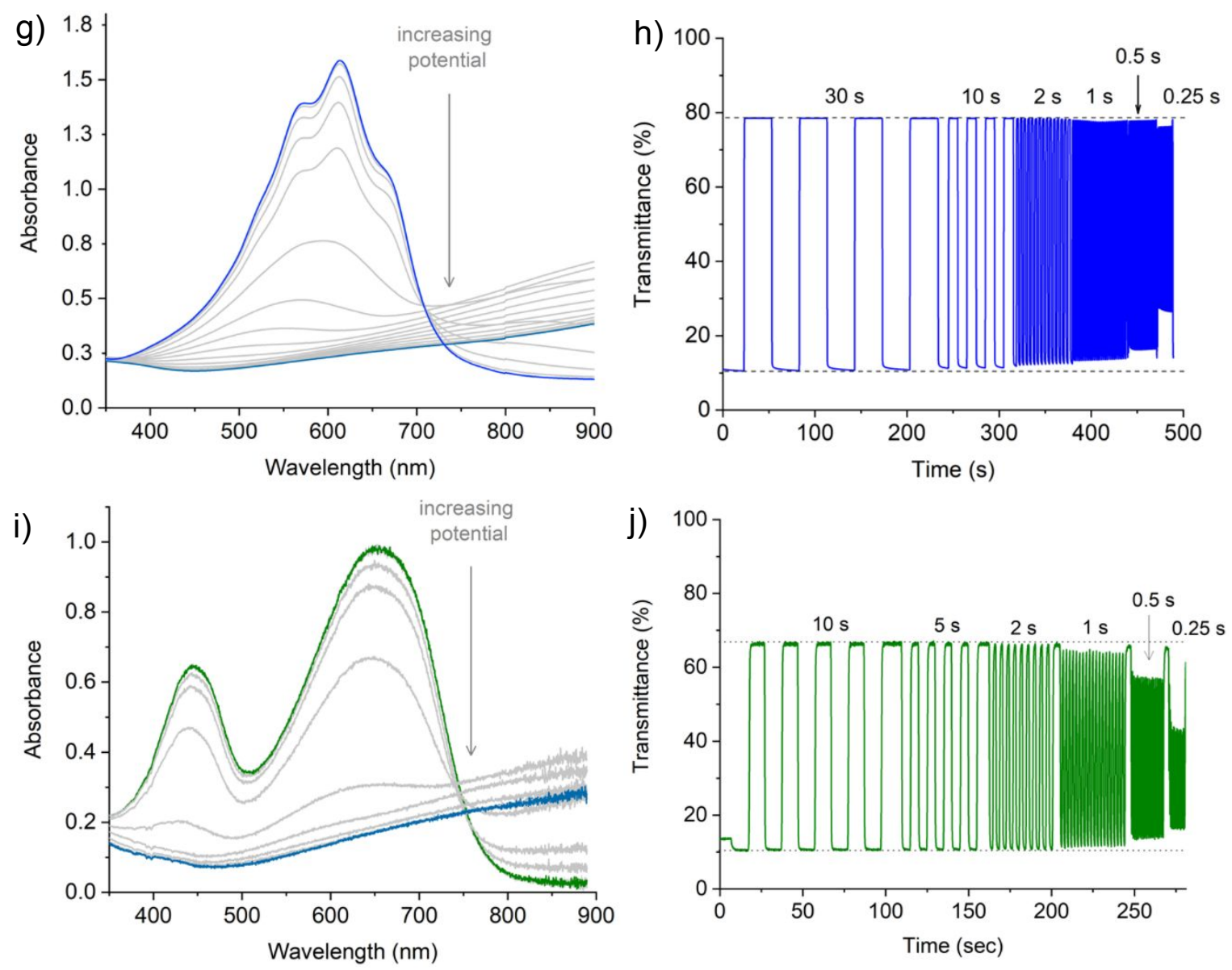

Figure S1. Potential dependent absorption spectra and switching kinetics on ITO/glass of a-b) ECP-Orange, c-d) ECP-Magenta, e-f) ECP-Purple, g-h) ECP-Blue, and i-j) ECP-Green. Spectra were recorded in $0.5 \mathrm{M} \mathrm{TBAPF}_{6} / \mathrm{PC}$ from $-0.5 \mathrm{~V}$ (ECP-Orange, ECP-Purple, ECP-Green) or -0.8 $\mathrm{V}$ (ECP-Magenta and ECP-Blue) to $0.8 \mathrm{~V}$. The switching kinetics were measured at $\lambda_{\max }$ by varying the pulse length from 10 to 0.25 seconds. 


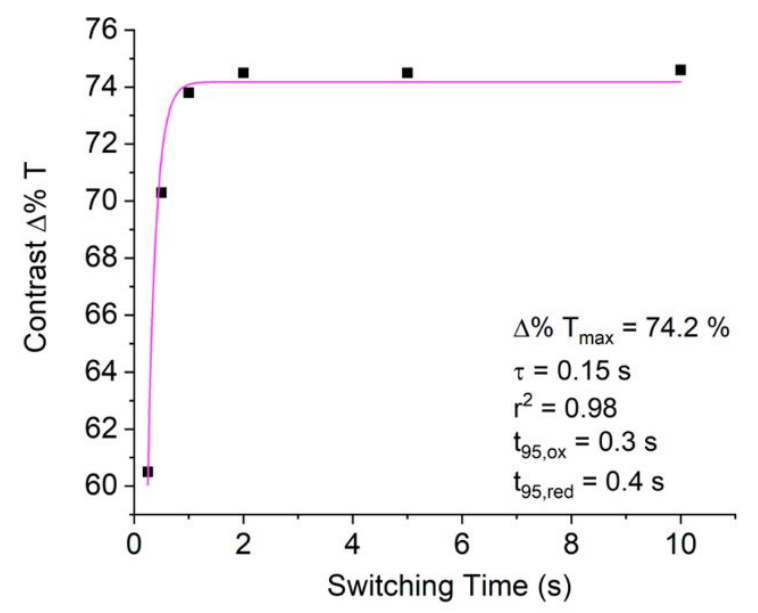

Figure S2. Exemplary switching time constant estimation for ECP-Magenta using the results from Fig. S1d.

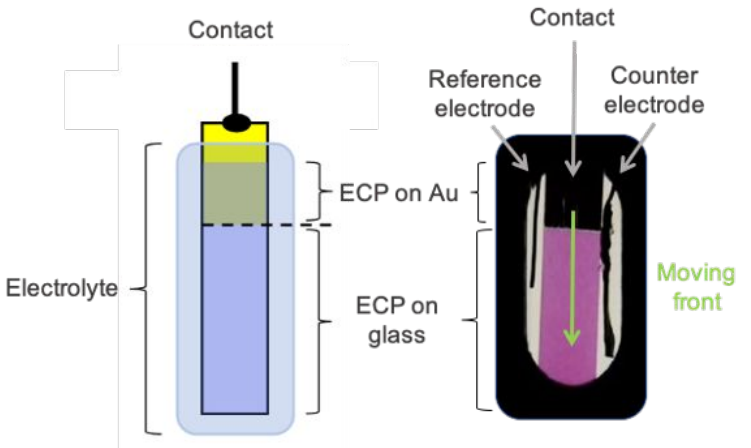

Figure S3. (left) Schematic of the Au patterned glass slide used in the moving front experiments and (right) photograph of the three-electrode cell used for capturing the videos and photographs of the moving front experiments.

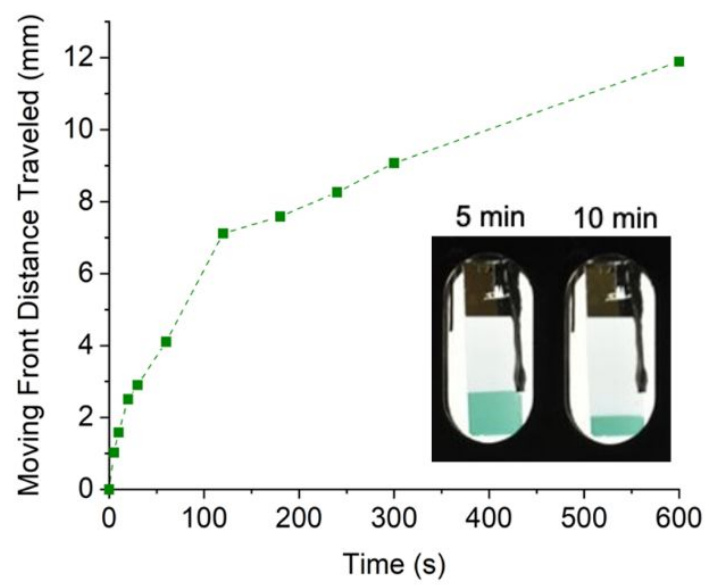

Figure S4. Photographs of ECP-Green after 5 and 10 minutes of electrochemical oxidation. 

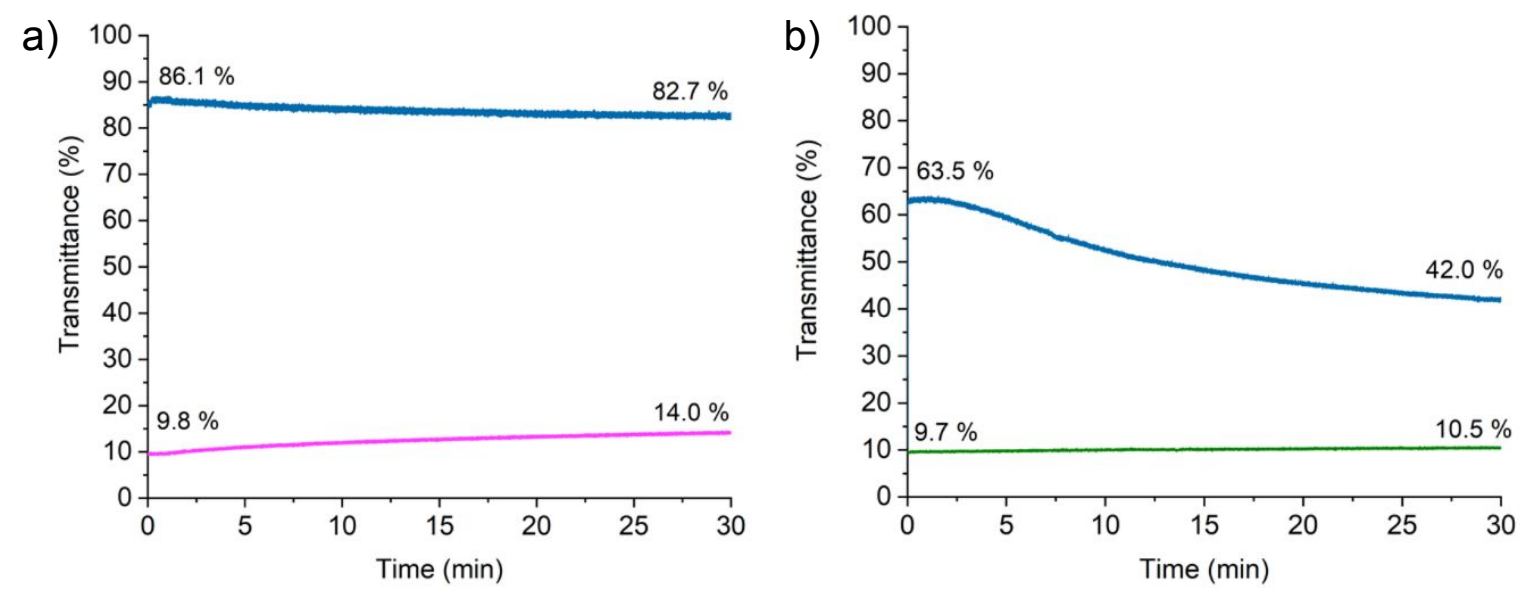

Figure S5. Optical memory of the colored (magenta/green) and clear states (blue) of a) ECPMagenta and b) ECP-Green films on ITO/glass in $0.5 \mathrm{M} \mathrm{TBAPF}_{6} / \mathrm{PC}$ measured at $\lambda_{\max }$ for 30 minutes at open circuit. 
a)

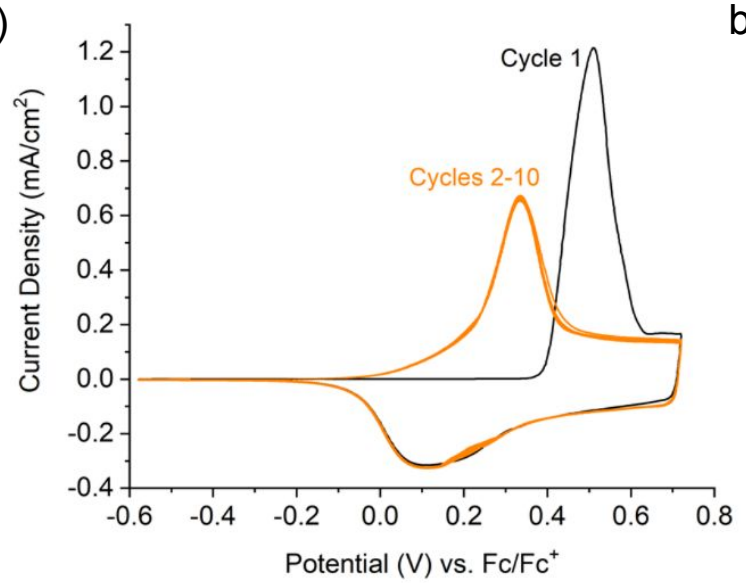

c)

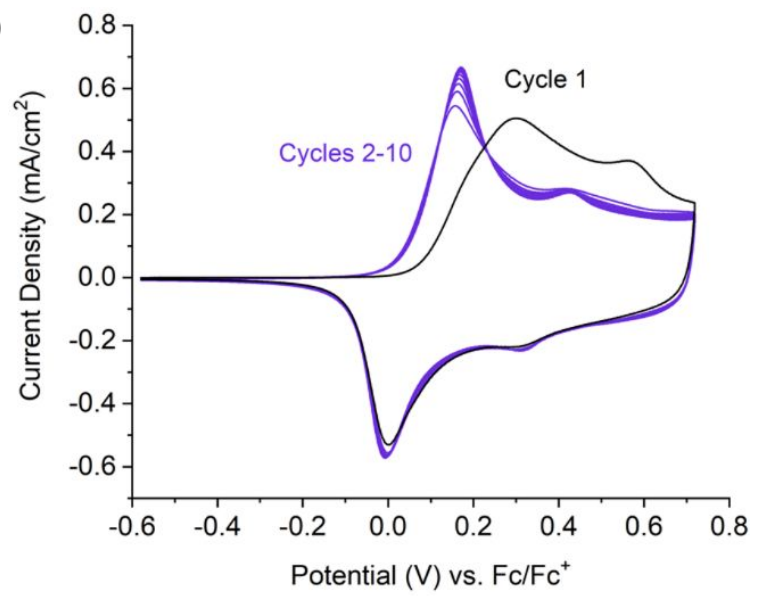

e)

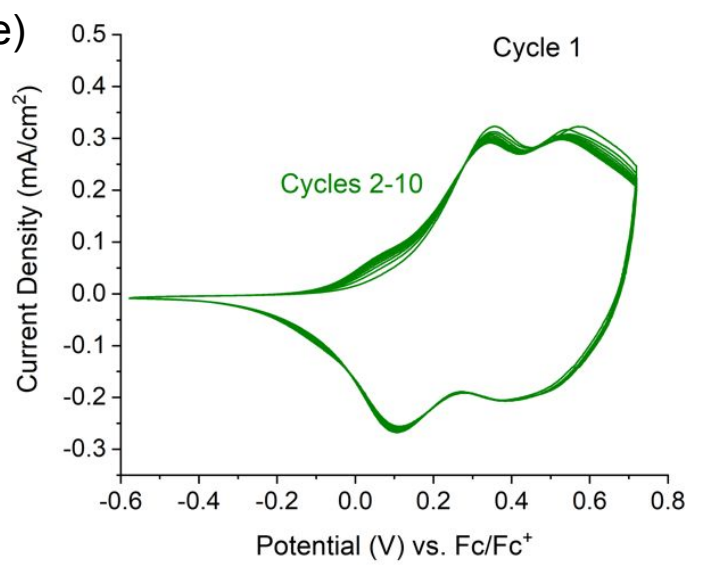

b)
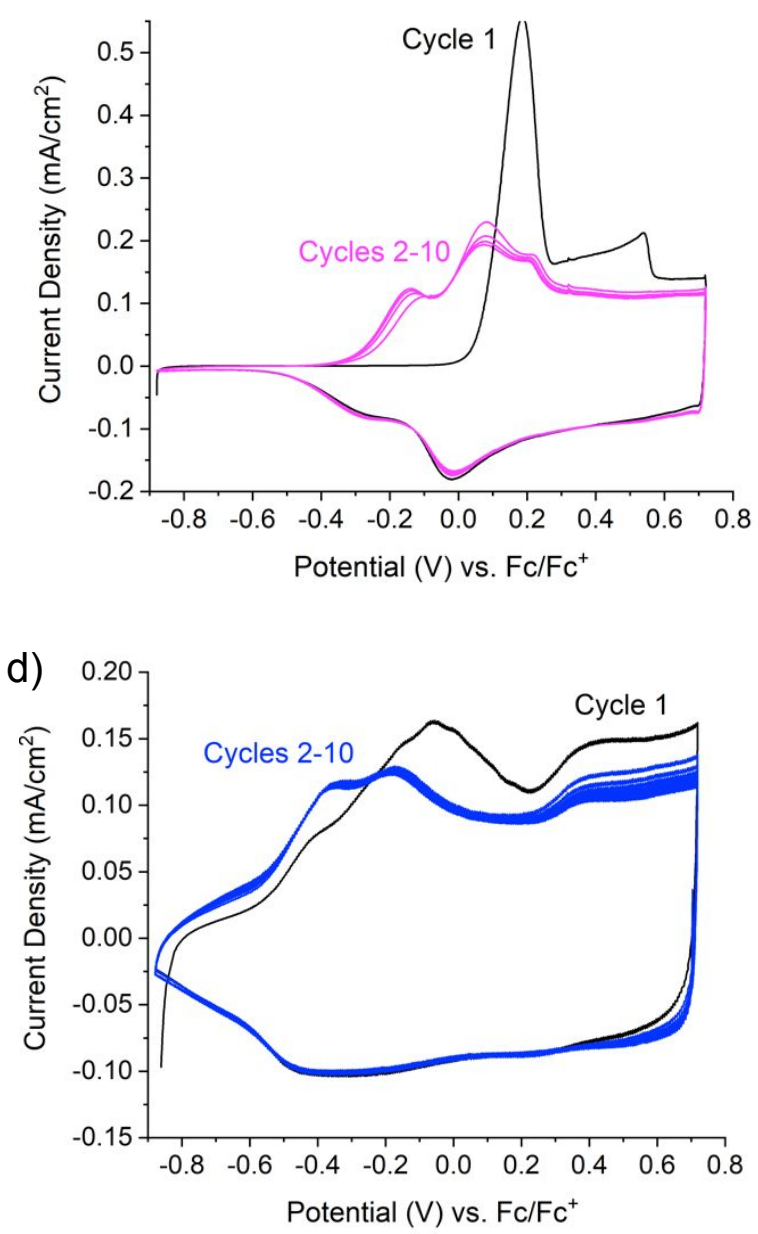

Figure S6. Cyclic voltammograms of a) ECP-Orange, b) ECP-Magenta, c) ECP-Purple, d) ECPBlue, and e) ECP-Green during electrochemical conditioning in $0.5 \mathrm{M} \mathrm{TBAPF} / \mathrm{PC}$ at $50 \mathrm{mV} / \mathrm{s}$ for 10 cycles. 

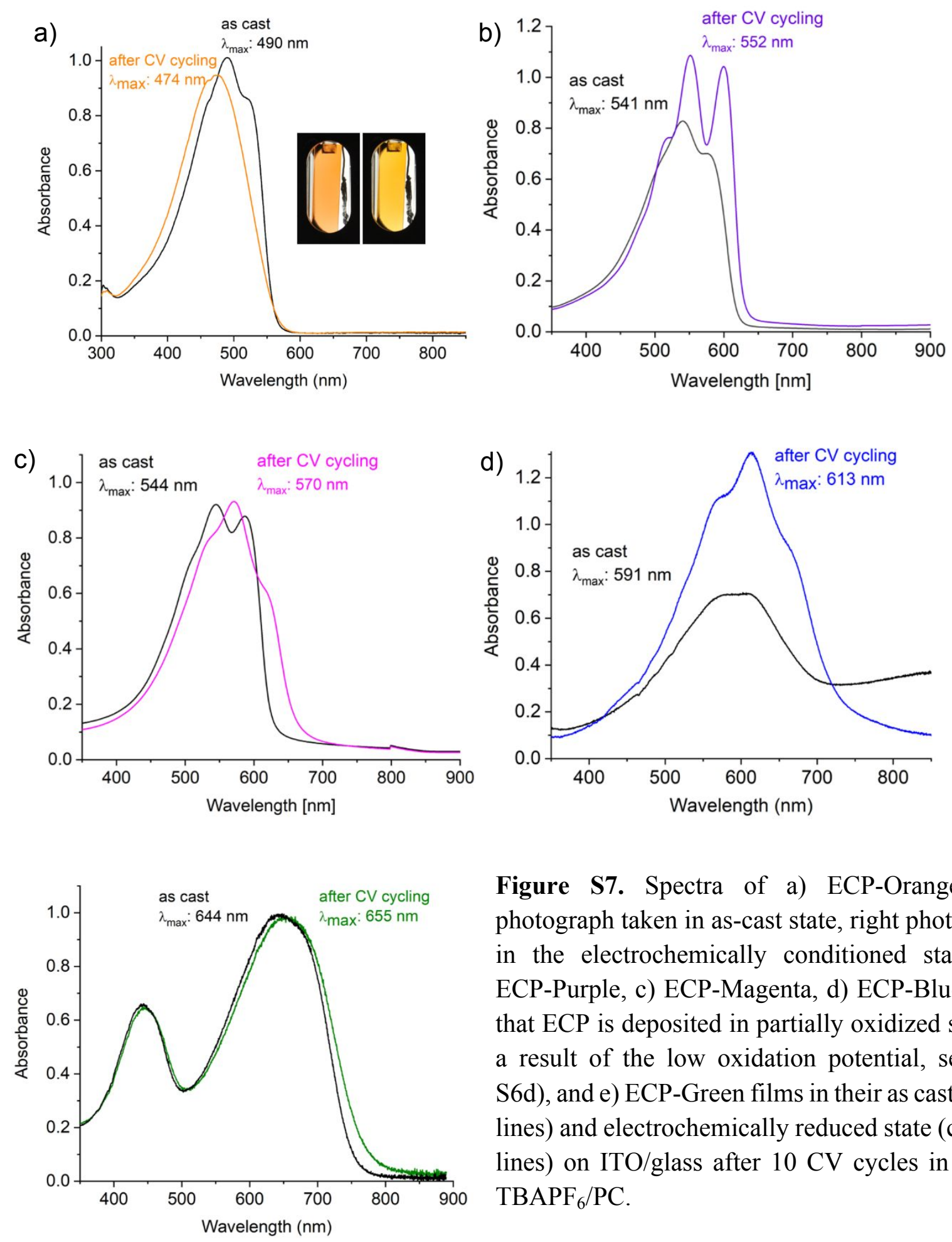

Figure S7. Spectra of a) ECP-Orange (left photograph taken in as-cast state, right photograph in the electrochemically conditioned state), b) ECP-Purple, c) ECP-Magenta, d) ECP-Blue (note that ECP is deposited in partially oxidized state as a result of the low oxidation potential, see Fig. S6d), and e) ECP-Green films in their as cast (black lines) and electrochemically reduced state (colored lines) on ITO/glass after $10 \mathrm{CV}$ cycles in $0.5 \mathrm{M}$ $\mathrm{TBAPF}_{6} / \mathrm{PC}$. 

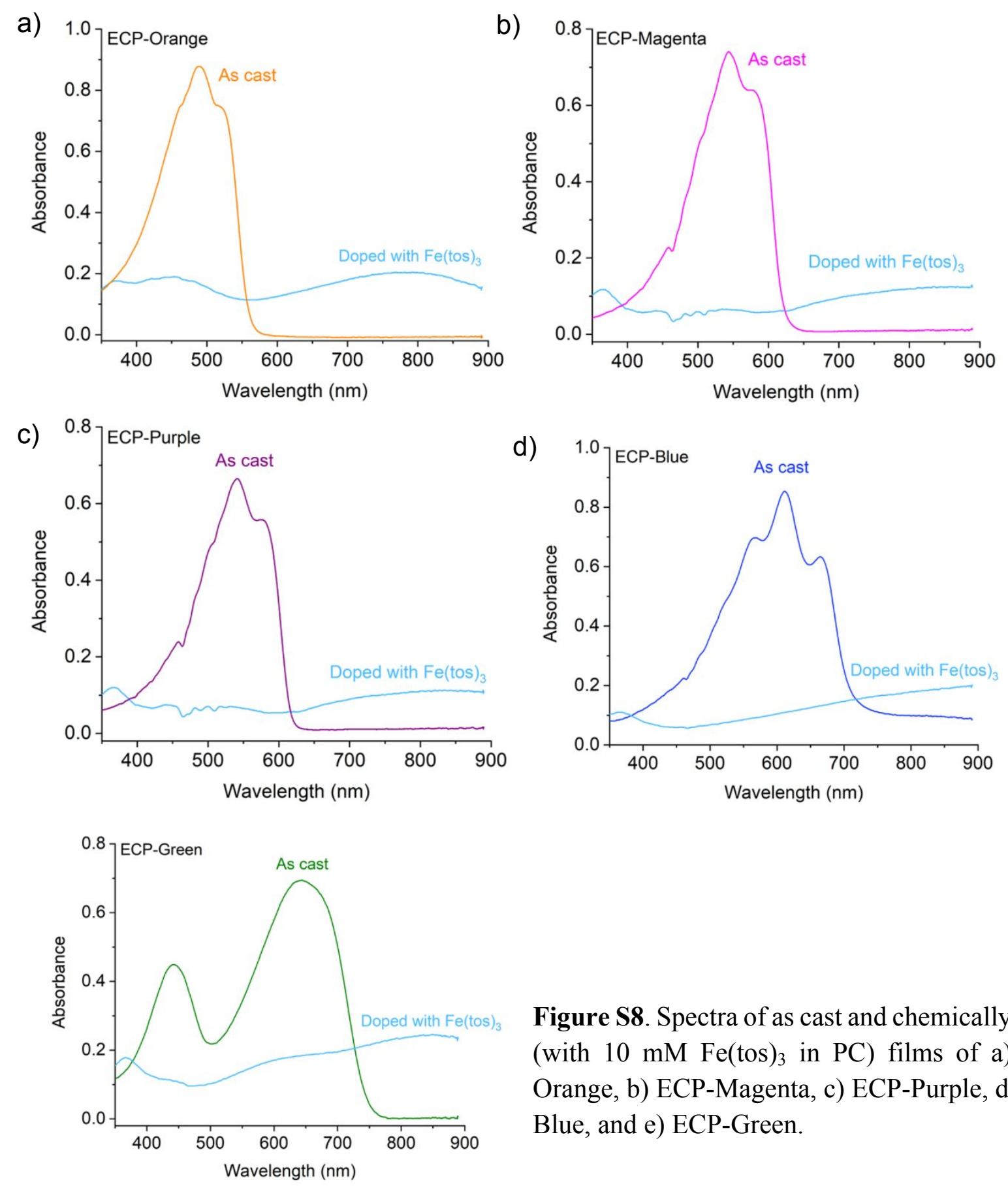

Figure S8. Spectra of as cast and chemically doped (with $10 \mathrm{mM} \mathrm{Fe}\left(\mathrm{tos}_{3}\right)_{3}$ in PC) films of a) ECPOrange, b) ECP-Magenta, c) ECP-Purple, d) ECPBlue, and e) ECP-Green. 

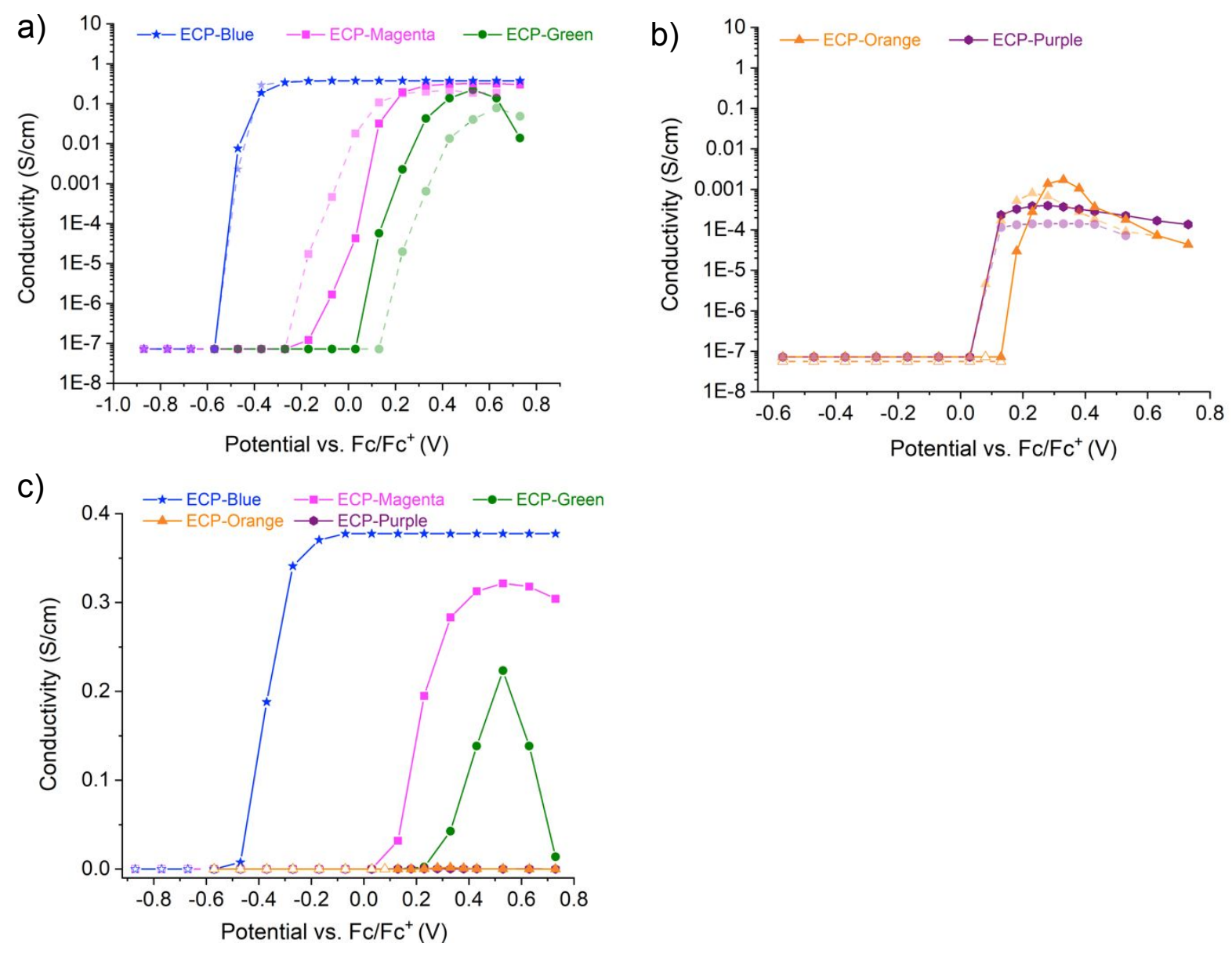

Figure S9. Potential dependent conductivity of a) ECP-Blue, ECP-Magenta, ECP-Green, and b) ECP-Orange, and ECP-Purple during bleaching/doping (solid dark lines) and recoloration/dedoping (dashed pale lines) in $0.5 \mathrm{M} \mathrm{TBAPF}_{6} / \mathrm{PC}$. Conductivity trends plotted in separate figures for clarity. c) Potential dependent conductivity of all ECP films in $0.5 \mathrm{M}$ $\mathrm{TBAPF}_{6} / \mathrm{PC}$ plotted on a linear scale. The detection limit for the instrument does not allow for conductivity values below $10^{-7} \mathrm{~S} / \mathrm{cm}$ to be measured; values below the detection limit are represented by empty symbols in a) and b). 

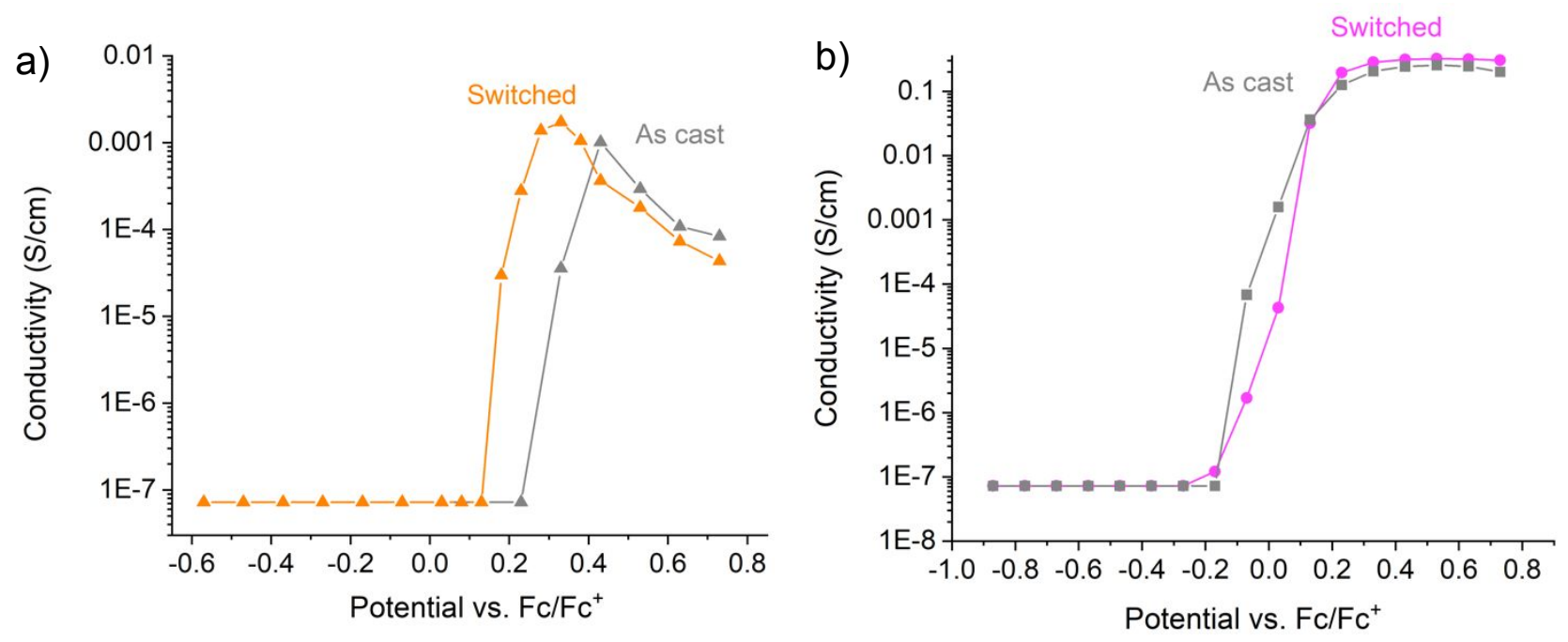

Figure S10. Potential dependent conductivity of a) ECP-Orange and b) ECP-Magenta films in their as cast (grey lines) and switched states in $0.5 \mathrm{M} \mathrm{TBAPF}_{6} / \mathrm{PC}$.

a)

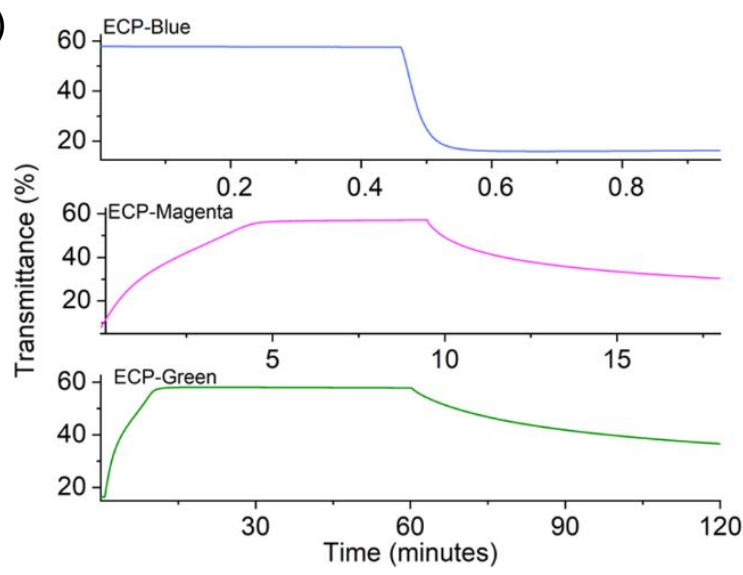

c)

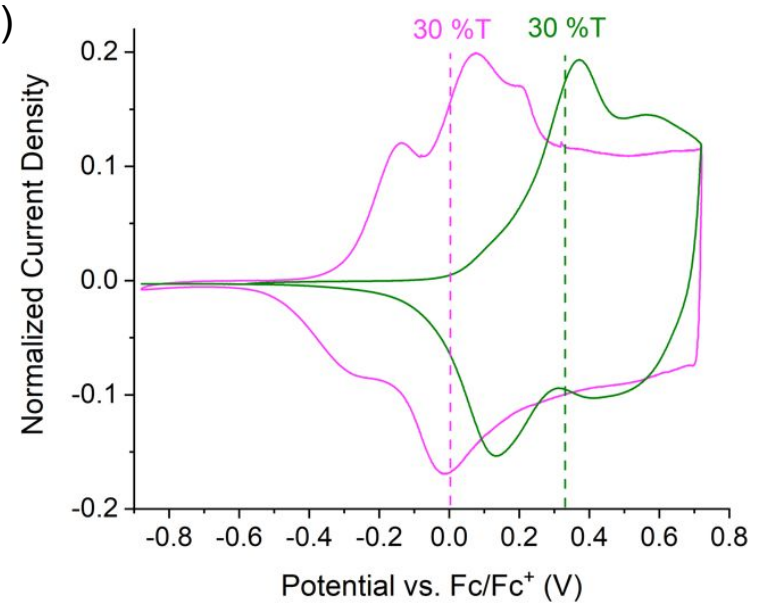

b)

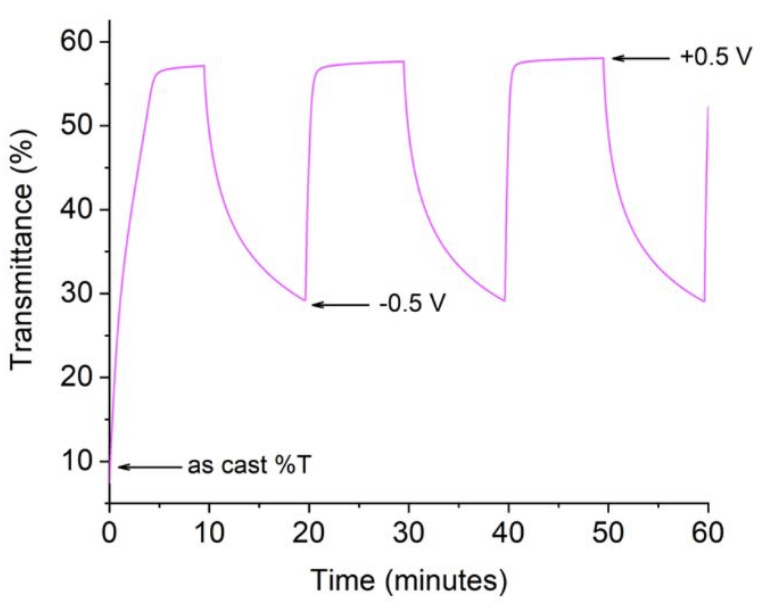

Figure S11. a) Transmittance as a function of time measured during the first switch of an as-cast ITO-free EC pixel (from top to bottom: ECPBlue, ECP-Magenta, and ECP-Green). b) The first three on/off switches of a Magenta pixel. c) Cyclic voltammograms of ECP-Magenta and ECP-Green films in $0.5 \mathrm{M} \mathrm{TBAPF} / 6$ on ITO/glass, the potential corresponding to an oxidation state with $30 \% \mathrm{~T}$ is highlighted by dashed lines. 
a)

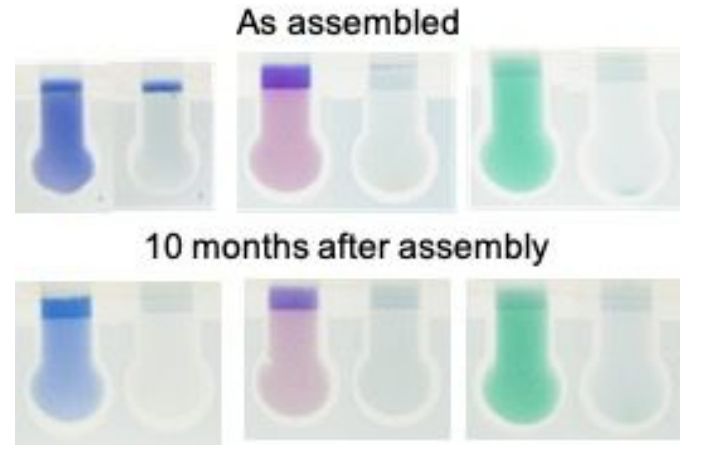

c)

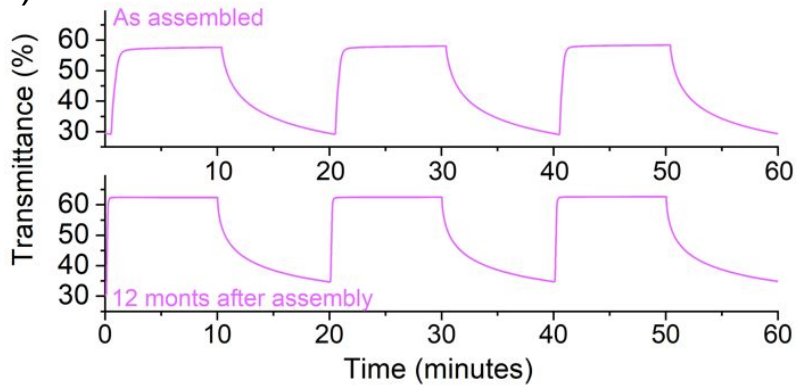

e)

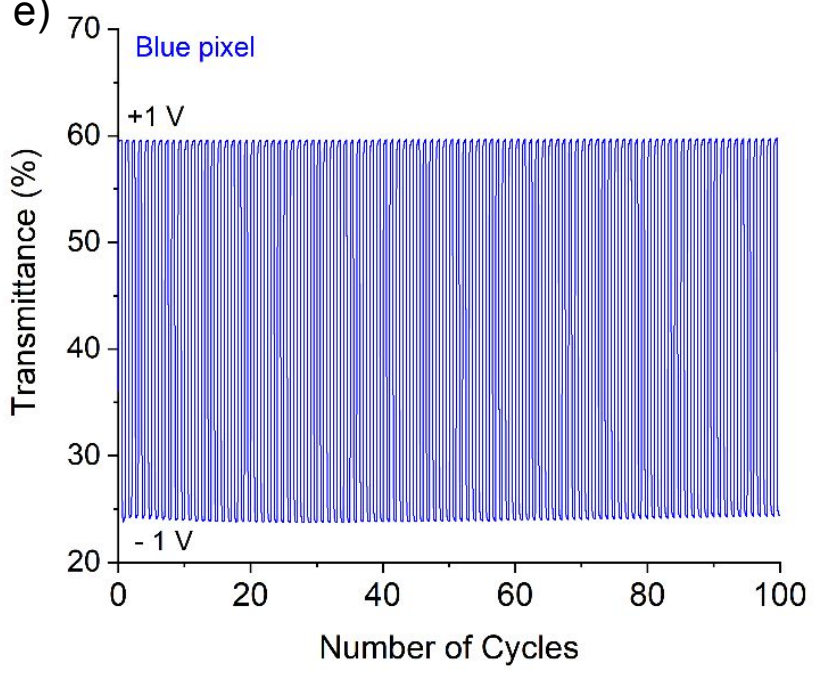

b)

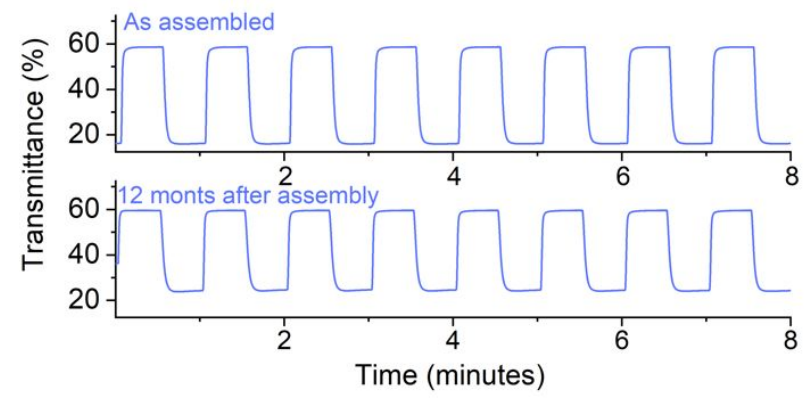

d)

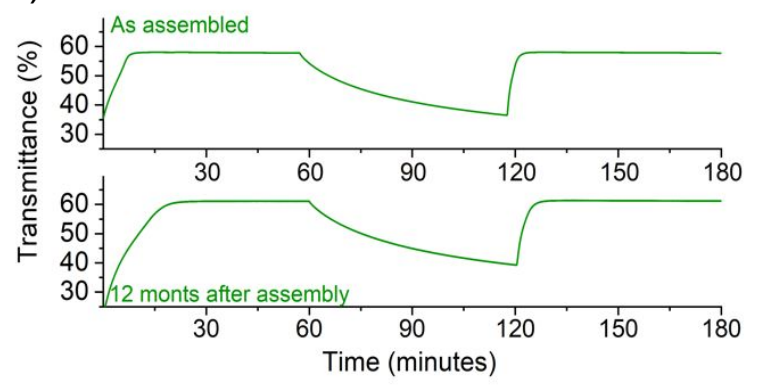

Figure S12. a) Photographs of as-assembled ITO-free EC pixels (top row) and the same pixels 10 months later (bottom row). Switching kinetics of a b) Blue pixel, c) Magenta pixel, and d) Green pixel in their as-assembled state (top curve) and after 12 months of storage (bottom curve). e) Switching kinetics of 12-month-old Blue device (100 cycles between, -1 V/ +1 V, 30 second switches). 


\section{REFERENCES}

(1) Christiansen, D. T.; Reynolds, J. R. A Fruitful Usage of a Dialkylthiophene Comonomer for Redox Stable Wide-Gap Cathodically Coloring Electrochromic Polymers. Macromolecules 2018, 51 (22), 9250-9258.

(2) Österholm, A. M.; Ponder, J. F.; De Keersmaecker, M.; Shen, D. E.; Reynolds, J. R. Disentangling Redox Properties and Capacitance in Solution-Processed Conjugated Polymers. Chem. Mater. 2019, 31 (1), 2971-2982.

(3) Estrada, L. A.; Deininger, J. J.; Kamenov, G. D.; Reynolds, J. R. Direct (Hetero)Arylation Polymerization: An Effective Route to 3,4-Propylenedioxythiophene-Based Polymers with Low Residual Metal Content. ACS Macro Lett. 2013, 2 (10), 869-873.

(4) Savagian, L. R.; Österholm, A. M.; Shen, D. E.; Christiansen, D. T.; Kuepfert, M.; Reynolds, J. R. Conjugated Polymer Blends for High Contrast Black-to-Transmissive Electrochromism. Adv. Opt. Mater. 2018, 6 (19), 1800594.

(5) Jones, A. L.; De Keersmaecker, M.; Pelse, I.; Reynolds, J. R. Curious Case of BiEDOT: MALDI-TOF Mass Spectrometry Reveals Unbalanced Monomer Incorporation with Direct (Hetero)Arylation Polymerization. Macromolecules 2020, 53 (17), 7253-7262.

(6) Salinas, G.; Frontana-Uribe, B. A. Analysis of Conjugated Polymers Conductivity by in Situ Electrochemical-Conductance Method. ChemElectroChem 2019, 6 (16), 4105-4117. 